\title{
MULHERES EM TRADUÇÃO: LITERATURA E INCLUSÃO SOCIAL
}

Women in Translation: Literature and Social Inclusion

\author{
Liliam Cristina MARINS (UEM) ${ }^{1}$ \\ Cielo Griselda FESTINO (UNIP) ${ }^{2}$
}

\begin{abstract}
RESUMO: O objetivo deste artigo é discutir as relações de poder e resistência por meio da tradução cultural, interlingual e literária provenientes de grupos considerados "minoritarizados", como é o caso das mulheres de diferentes culturas. Entendemos que no ato da tradução as perspectivas ideológicas se manifestam não somente na temática, mas também no uso da linguagem, dos estilos narrativos e das estratégias de tradução que as tornam uma arma de resistência. Para ilustrar essa discussão, consideramos a apropriação do texto shakespeariano Romeu e Julieta por uma mulher da terceira idade, parte de uma comunidade maior, embora marginalizada - a Universidade da Terceira Idade. Em um movimento de expansão interpretativa, o gênero dramático e o modus operandi textual são ressignificados, a partir de uma perspectiva comunitária, social e ideológica. Logo, consideramos o que significa o ato tradutório em comunidades plurilíngues como a indiana, nos focando nas traduções de contos escritos por mulheres, sobre temáticas femininas, nas línguas vernáculas da Índia traduzidas para o inglês assim como para outras línguas regionais. Essa discussão está baseada no conceito de expansão interpretativa de Monte Mór (2015) e da tradução de Baker (2006), Derrida (2005), Devy (1997), Sobral (2008) e Tymockzo (2006).
\end{abstract}

PALAVRAS-CHAVE: tradução; resistência; autoria feminina; expansão interpretativa; visibilidade; grupos minoritários.

\begin{abstract}
The aim of this article is to discuss the relations of power and resistance through cultural, inter-lingual and literary translation coming from groups considered as minorities, such as the case of women. We understand that in the act of translation ideological perspectives are manifested not only in the theme, but also in the use of language, narrative styles and translation strategies that turn them into a weapon of resistance. To illustrate this discussion we consider the appropriation of the Shakespearean play, Romeo and Juliet, by an elderly woman, member of UNATI, University for Elderly Citizens. In a movement of interpretative expansion, the dramatic genre and the textual modus operandi are re-signified from a communitarian, social and ideological perspective. We then consider what the translation act means in plurilingual communities such as India, focusing on the translation of stories written by women, and on women related themes, in the vernacular languages of India

\footnotetext{
${ }^{1}$ Professora no Curso de Letras e no Programa de Pós-Graduação em Letras na Universidade Estadual de Maringá (UEM). Doutora em Letras pela mesma universidade. liliamchris@ hotmail.com

${ }^{2}$ Professora de Literaturas de Língua Inglesa na Universidade Paulista (UNIP). Doutora em Literatura Indiana de Língua Inglesa pela Universidade de São Paulo (USP), com pós-doutorado pela Universidade de Minas Gerais (UFMG). cielofestino@gmail.com
} 
translated into English as well as into other regional languages. This discussion is based on the concepts of interpretive expansion (MONTE MÓR, 2000), and translation (DEVY, 1997; BAKER, 2006; DERRIDA, 2005; SOBRAL, 2008; TYMOCKZO, 2006).

KEYWORDS: translation; resistance; women authorship; interpretative expansion; visibility; minorities.

\section{INTRODUÇÃO}

Em um mundo atualmente marcado pela busca de valorização da diversidade, vozes, antes silenciadas, excluídas e sufocadas por relações dominantes de poder, encontram, nas discussões pós-modernas de diversas áreas do saber, terreno fértil para sua legitimação e valorização institucional (BOITO; MARINS, 2017). Tal visibilidade força sua consolidação em diferentes modos e meios de resistência ao poder imposto sobre elas, "que constrói identidades, nelas fixa estereótipos, discriminações, produzindo subjetividades que não encontram lugar nas sociedades hegemônicas de discurso" (CORACINI, 2010, p. 107).

Nesse sentido, as discussões desenvolvidas a partir da tradução demonstram ser especialmente frutíferas na empreitada cujo foco está na problematização da linguagem, na diferença, bem como nas discussões acerca das relações de poder e resistência (RAJAGOPALAN, 2003; CORACINI, 2010). O objetivo deste artigo é, assim, discutir as relações de poder e resistência da/pela/na tradução cultural, interlingual e literária provenientes de grupos considerados minoritários, como é o caso das mulheres de diferentes culturas, levando em conta as suas perspectivas ideológicas que se manifestam não somente na temática, mas também no uso da linguagem, dos estilos narrativos e das estratégias de tradução que as tornam em uma arma de resistência.

Na primeira parte do artigo, a tradução, pensada segundo um viés pós-moderno e derridiano, será abordada enquanto promotora da inclusão social ao possibilitar tanto a expansão interpretativa do texto (MONTE MÓR, 2015; 2018), como a democratização do acesso a produtos culturais antes restritos a determinados grupos/línguas/ lugares/meios de prestígio. Entendemos, assim, como tradução, qualquer movimento interpretativo convergindo (e divergindo) com outro texto. De forma específica, para ilustrar esta discussão, o ponto de partida é a apropriação da peça shakespeariana Romeu 
e Julieta ${ }^{3}$ por uma mulher da terceira idade, parte de uma comunidade maior, embora "minoritarizada" - a Universidade da Terceira Idade -, a qual, em um movimento de expansão interpretativa, ressignificação gênero dramático e o modus operandi textual e interpretativo, a partir de uma perspectiva comunitária, social e ideológica.

$\mathrm{Na}$ segunda parte do artigo, consideramos o que significa o ato tradutório em comunidades plurilíngues como a indiana, nos focando nas traduções de contos escritos por mulheres sobre temáticas femininas, nas bhashas, línguas vernáculas da Índia, traduzidas para o inglês, assim como para outras línguas regionais. Consideramos, em particular, o caso das editoras Stree Katha e Kali for Women. Nosso argumento é que as obras literárias têm a possibilidade de provocar mudanças em uma sociedade. Quando traduzidas para outras línguas, não somente chamam a atenção da comunidade nacional e internacional, mas também provocam mudanças na comunidade local onde se originaram. Essa discussão está fundamentada a partir do pensamento de teóricos da tradução que têm se voltado para o tema da tradução como forma de engajamento político (DEVY, 1997; TYMOCKZO, 2006; BAKER, 2006).

Esta discussão se faz especialmente importante neste momento histórico/político /social/cultural, no qual a tradução precisa ser reconhecida enquanto meio de representação da diferença e de resistência aos modelos tradicionais de produção do conhecimento e da cultura. De forma mais específica, olhar para essas manifestações tradutórias, culturais, linguísticas e literárias, pelas lentes da diferença, pode promover uma nova roupagem do substantivo "poder", enquanto sentido arbitrário que representa a autoridade inquestionável do centro sobre a periferia, para o verbo "poder", enquanto sentido possível que reflete a capacidade e a oportunidade de mudança (BOITO; MARINS, 2017).

\section{LITERATURA, TRADUÇÃO E VISIBILIDADE}

Muitos textos das tradições literárias definidas como "não canônicas" vão além da prática estética para se tornar armas de resistência. Como já argumentado previamente (FESTINO, 2015, p. 26-27), essas histórias traduzem os conflitos de uma comunidade em palavras e, eventualmente, essas palavras são traduzidas em ações que

\footnotetext{
${ }^{3}$ A instituição é vinculada à Universidade Estadual de Maringá e o contexto de produção é um blog, elaborado e alimentado pelos alunos, a respeito de William Shakespeare como parte de uma disciplina de literatura ofertada no ano de 2012.
} 
têm como objetivo achar soluções para esses conflitos e, assim, transformar-se em novas histórias.

As obras literárias, como todas as narrativas, estão profundamente entrelaçadas com a vida da comunidade de onde se originam. Da mesma forma que não há comunidade sem língua, não há comunidades sem histórias. Ao serem contadas ou silenciadas, essas histórias revelam tudo: o que a comunidade faz ou se recusa a fazer; em que acredita ou o que considera um preconceito; suas virtudes e também suas profundas injustiças. Quando consideradas dessa forma, como explica Rita Felski (2008), os textos literários não são apenas "objetos" de conhecimento, mas "fontes" de conhecimento, porque articulam tanto as crenças e conflitos de uma comunidade, assim como os caminhos que procura para resolvê-los (FELSKI, 2008, p. 11). Além disso, como a autora também argumenta, se as obras de arte "[...] surgem do social e voltam para o social" (FELSKI, 2008, p. 12), nesse processo, elas não permanecem as mesmas desde que estejam sujeitas a múltiplas interpretações que ajudam a enxergar a experiência social da qual surgiram de maneira diferenciada.

Quanto à ação direta que elas possam ter sobre a comunidade, pode-se argumentar que os textos literários não têm o poder de mudar a sociedade completamente para o bem ou para o mal. Contudo, como eles recriam os seres humanos no seu cotidiano, por meio de metáforas sugestivas que relacionam o afetivo ao racional, elas ajudam a conscientizar os leitores sobre diferentes temáticas de modo que possam contribuir para estabelecer um vínculo firme com o político. Por sua vez, o político se traduz em um apelo para a inclusão, a justiça, e a mudança.

Nesse contexto, a tradução pode ser uma arma política fundamental ora para articular a identidade de uma comunidade marginalizada, ora para trazer determinados temas para a consideração do público além da comunidade local. Conforme Mona Baker (2006, p. 423), tanto a tradução como a não tradução desses textos é algo igualmente político, em particular, após as mudanças nos estudos da tradução que passaram a considerar que o que se deve levar em conta no ato de traduzir não é somente a sua qualidade linguística ou estética, noutras palavras, o que tradicionalmente tem se considerado como uma boa tradução, mas o que significa a tradução de certos textos em um determinado contexto social, já que essas obras literárias podem ser fundamentais para lutar contra a censura, a repressão, a dominação política. Mais do que um exercício linguístico e mecânico, ou uma transposição linguística ou criação 
literária, acrescenta a autora, a tradução é uma atividade ética, política e ideológica. Assim entendida, a tradução não é somente a produção de um texto, como também fala Maria Tymockzo (2006, p. 455), mas um ato em que o processo é tão importante quanto o produto final.

Assim entendida, a tradução pode funcionar, em especial, para grupos minoritários, como um ato de resistência. Além de dar visibilidade para gêneros considerados marginalizados, ora pela comunidade onde são produzidos (como seria o caso das mulheres indianas nas línguas vernáculas ou as mulheres da terceira idade) ora pelo seu estilo(como é o caso de narrativas orais, que, devido à valorização da cultura grafocêntrica, muitas vezes, são considerados registros ilegítimos), a tradução também pode fazer sobreviver (DERRIDA, 2005) textos antes restritos a determinados espaços, línguas e culturas e, ainda, validar discursos e sujeitos silenciados por um sistema regulado por relações de poder (CORACINI, 2010).

Quando compreendida como um ato político, a tradução se distancia de noções prescritivistas como fidelidade, equivalência, essência, original, autoria, entre outros e se aproxima da ideia de expansão interpretativa (MONTE MÓR, 2015; 2018), ou seja, rompe com sua compreensão enquanto restituição de uma essência encarcerada em um “original” (que é sagrado, intocável) em direção ao conceito de apropriação, transformação e reescritura.

É por isso que Sobral (2008) defende a tradução como um pós-gênero - não aspira a ser um espelho de seu "original", tampouco nega seu caráter palimpsestuoso e suas relações intertextuais com seu texto de partida. É um gênero outro, terceiro, heterogêneo, transfigurado:

\footnotetext{
Um trans-gênero, porque é uma ação de recorte do mundo que recorta um recorte, um estranho gênero que constitui vários outros gêneros, que origina pelas mãos de um novo autor (ou co-autor) um discurso que vem de outro discurso e que já tem um autor (SOBRAL, 2008, p. 69).
}

Há, nesse sentido, um eco de vozes, gêneros, interpretações que falam na e pela tradução, distanciando-a de uma concepção meramente reprodutiva e aproximando-a de uma noção mais colaborativa e caleidoscópica. Ela não nega, assim, sua relação com outro(s) texto(s), mas também não se deixa apagar por ele(s).

Essa imagem caleidoscópica da tradução também pode ser encontrada nos estudos de Quine (2000), quando o teórico lança mão da técnica de fotografia double- 
exposed photograph, a qual envolve a convergência de duas imagens, gerando, por sua vez, uma terceira,para representar o processo tradutório. Isso significa que, quando traduzimos, assumimos o papel de agentes e, como sujeitos sócio-historicamente situados, construímos sentidos sob as lentes do nosso olhar sobre o mundo (em toda sua complexidade e diversidade). É este o conceito de tradução que norteia nossa discussão: uma forma de expansão das interpretações que construímos.

\section{MULHER NA TERCEIRA IDADE EM TRADUÇÃO: EXPANDINDO PERSPECTIVAS E INTERPRETAÇÕES NO CONTEXTO BRASILEIRO}

O olhar para a tradução enquanto possibilitadora deste movimento de expansão de sentidos está pautada no conceito de habitus interpretativo cunhado por Monte Mór (2018) - que, por sua vez, partiu da noção de habitus linguístico, de Bourdieu (2007) -. O habitus interpretativo está relacionado à construção de sentidos dentro da convivência do indivíduo com o social, ou seja, como a interpretação desse indivíduo é guiada por um conjunto de práticas sociais e ideológicas dentro do sistema de disposições formadas nessa convivência. Os sentidos são produzidos, nessa perspectiva, sempre considerando a posição individual e coletiva do sujeito, opondo-se a uma concepção tradicional e positivista que busca um sentido único e estável, uma verdade e uma validade no texto.

A expansão interpretativa, para a teórica, objetiva justamente romper com os modos de significar e promover uma abertura no círculo interpretativo (antes impenetrável, inquebrável e apenas tangenciado), estendendo o horizonte de perspectivas de construção de sentidos. Sobre esse processo, Monte Mór chama de meaning making, já que interpretamos os eventos diários em sua relação com o mundo que nos cerca de acordo com nossos círculos de relações sociais (MONTE MÓR, 2018, p. 330). Sendo assim, o fazer sentido no mundo é particularmente relevante para determinados grupos sociais em busca de voz, legitimação e visibilidade. Este parece ser o caso de sujeitos que se encontram na terceira idade, em especial, das mulheres, as quais são duplamente marginalizadas: por serem mulheres e por estarem em uma fase da vida que, muitas vezes, as exclui da vida ativa e social. Repentinamente, seu papel de agência, seja na vida social, no trabalho ou até mesmo nos afazeres domésticos, exercida por toda uma vida, lhes é negada, usurpada e proibida. 
Como um espaço construído para (re)inserção social dos sujeitos da terceira idade, a Unati (Universidade da Terceira Idade) se consolida por volta da década de 1980 e, enquanto projeto de extensão, está presente atualmente nas mais diversas universidades brasileiras. Seu objetivo não é apenas preencher o tempo ocioso dos sujeitos na terceira idade, mas reinseri-los socialmente, já que, depois de alguns meses de aposentadoria, muitos sentem com pesar esse "tipo de lâmina que desce sobre eles [...] e, bruscamente, por serem aposentados, não são mais úteis" (VELLAS, 2009, p. 93). As Unatis não visam, assim, uma formação para o mercado de trabalho, mas para a convivência social (seja dentro da própria família ou em outros espaços que ocupam).

As disciplinas ofertadas na grade da Unati, que é caracterizada por um ensino não formal, contemplam as mais variadas áreas do saber e são ministradas pelos próprios docentes das instituições às quais se vinculam. Destaco, no rol dessas disciplinas, as produções das disciplinas de literatura ministradas, desde 2013, na Unati da Universidade Estadual de Maringá, que tem como objetivo aproximar os alunos da terceira idade dos chamados "clássicos" da literatura brasileira e de língua inglesa a partir de traduções e adaptações. De acordo com Vellas (2009), os sujeitos da "terceira idade" precisam, além de ter contato com as obras de arte consideradas canônicas, ser produtores dela, participando de sua criação.

No texto Crítica e letramentos críticos: discussões preliminares, Monte Mór ressalta a importância de não se validar apenas o "conhecimento autorizado para realizar análises de obras de artes ou literárias", mas buscar libertar os leitores "das amarras dos 'sentidos dados nos textos pelos autores"” (MONTE MOR, 2015, p. 40), permitindo que atuem como protagonistas de suas leituras, histórias e escolhas. Esse protagonismo precisa ser considerado na abordagem, em especial, dos bens culturais, já que, enquanto forem considerados como constituintes de uma cultura engessada e para poucos, eles servirão como depósitos de um conhecimento que pouco se relaciona com a cultura popular transformativa e com a formação crítica dos cidadãos.

A fim de ilustrar como vozes silenciadas podem se tornar visíveis pela tradução, quando esta é abordada enquanto ferramenta possibilitadora de um movimento de expansão interpretativa, destaco a produção a seguir - uma reescrita de Romeu e Julieta, divulgada no blog a respeito de William Shakespeare e que foi criado pelos alunos da Unati, em 2012: 
DES....ENCONTRO ${ }^{4}$

com Shakespeare na terceira-idade

MARIETA amava TADEU

que a amava muito também.

A diferença de idade

(vinte anos ou mais)

era motivo pros filhos

desaprovarem a união.

Por trás, motivos escusos:

preconceito, ciúmes, pensão...

Tanto fizeram os filhos, que Tadeu injuriado

afastou-se de Marieta

em profunda depressão.

Perdeu o emprego, a casa

Perdeu amigos, parentes

Bebeu,cheirou de montão.

Quando morreu de"overdose"

Só "Marieta"... "Marieta"... balbuciou.

Sabendo disso os filhos

- mal disfarçavam o alívio -

disse nada Marieta.

Naquela noite em seu quarto enfeitou-se com esmero

Perfumou-se com essências

rosas,...lírios, ... violetas.

De manhã quando a encontraram

lívida, hirta no leito

jaziam também ao lado

intocados, inda nos vidros

seus remédios de coração.

Depois da noite velada pelos filhos conduzida em cerimônia solene

à nova morada escolhida

constatou-se com surpresa:

Por ironia da vida

- nem sempre bem explicada -

lado a lado eram os jazigos

dos amantes separados.

\footnotetext{
${ }^{4}$ Disponível em: http://unatishakespeare.blogspot.com.br/search?updated-max=2012-09-28T08:43:0007: 00\&max-results=7 Acesso em: 24 maio 2019.
} 
A presença de conflitos, crises e contradições enfrentadas por esse sujeito na terceira idade, destacada pelos termos "preconceito", "pensão", “depressão", "jazigos", marca-se enquanto um ato de resistência, já que desestabiliza as travas de segurança da história "original": a desaprovação do romance era dos filhos e não dos pais; a intriga entre as família se sustenta na pensão/aposentadoria e não na rivalidade de poder entre as famílias; o sentimento de tristeza pelo impedimento da história de amor foi atualizada pela depressão e pelo uso de drogas, tema de discussão na pós-modernidade;o "elemento trágico" deixou de ser o ato de "ingerir o veneno" para "deixar de tomar o remédio". Se partirmos da ideia derridiana de pharmakon, que pode ser veneno ou remédio, há, nesta expansão interpretativa, a transformação do modus operandi da história: na terceira idade, o que mata é deixar de consumir o "veneno" e não "consumilo”. Segundo Marins e Prado (2013), é perceptível não apenas uma agência deste sujeito, mas também uma maior afirmação identitária, uma vez que a temática da terceira idade materializa-se, enquanto escolhas tradutórias e discursivas, como contraponto à história "original” dos jovens amantes.

Assim, a expansão interpretativa do texto shakespeariano pode representar a percepção de que

os valores têm origem nos contextos e grupos sociais aos quais cada um pertence (bairro, classe econômica, faixa etária, gênero masculino ou feminino, região geográfica, profissão); a influência do contextos social em sua formação como indivíduo e cidadão, e na formação dos outros com os quais ele convive, não como algo determinístico, mas sim como fator constitutivo (MONTE MÓR, 2018, p. 330, grifo nosso).

Nessa perspectiva mais comunitária, é possível desenvolver nos sujeitos a noção de que os grandes espaços são constituídos, por sua vez, de espaços menores (mas não menos importantes) e isso pode contribuir para "desfazer estereótipos discriminatórios" (MONTE MÓR, 2018, p. 331), como acontece com o grupo da terceira idade - ainda marginalizado em termos políticos, econômicos e sociais.É nesse sentido que, para romper um habitus regulatório na interpretação, a teórica propõe que os leitores sejam colocados na situação de autores das produções de sentidos, o que desvia "de um direcionamento convergente" (MONTE MOR, 2018, p. 321), em direção a uma pluralidade de possibilidades interpretativas, a uma emancipação interpretativa.

Ao relatar uma experiência docente no capítulo Letramentos críticos e expansão de perspectivas: diálogos sobre práticas, Monte Mór afirma ter notado que as leituras inicialmente realizadas por seus alunos podiam não representar, de fato, suas 
interpretações, mas as leituras "autorizadas", "aceitas", pelo professor e pela instituição reguladora nas quais se encontram (MONTE MOR, 2018, p. 317). No caso da reescrita realizada pela aluna da terceira idade, há, além da ruptura dessa leitura institucionalizada de Romeu e Julieta, também um distanciamento da história romantizada comumente compartilhada pelo senso comum, aproximando-se, assim, de uma postura mais crítica e social.

Ao pensarmos que toda tradução opera no campo de tensão e convergência entre línguas/culturas, modos de representação e condições sócio-histórico-ideológicas particulares, não podemos conceber a tradução enquanto resgate de um único sentido, desconsiderando o atravessamento do sujeito (BOITO; MARINS, 2017).

A negociação entre o homem e o mundo é mediada pela interpretação e nunca pode encontrar seu estado de saturação, uma vez que o texto é apenas um ponto de partida em direção a um leque de possibilidades interpretativas. Ou seja, o compreender está relacionado "com ser no mundo" e "toda tradução [...] é sempre gênero de interpretação" (GADAMER, 2002, p. 382; 395) empreendido por um sujeito-leitor que faz ecoar todas as vozes que falam na teia de sentidos e que resultam no texto traduzido.

Essa plurivocalidade, que sempre existiu, mas foi sufocada, desperdiçada, reprimida, encontra nas brechas abertas pela pós-modernidade a grande oportunidade para sua visibilidade. A tradução enquanto expansão interpretativa é um dos caminhos para se promover essa visibilidade ao valorizar a diversidade epistemológica, as diferentes experiências cognitivas e linguísticas e os mais variados universos simbólicos, como é o caso de tradução de literatura escrita por mulheres e sobre mulheres nas línguas indianas para o inglês e para outras línguas regionais.

\section{PLURILINGUISMO, LITERATURA E TRADUÇÃO NA ÍNDIA}

$\mathrm{Na}$ Índia, há 16 línguas oficiais, entre elas a língua inglesa. Cada um dos estados indianos se constitui na base de "uma língua, um estado". Por sua vez, essas línguas não são consideradas como unidades separadas, mas estão profundamente interrelacionadas. Suresh Canagarajah e Hina Ashtraf definem Índia como um país "plurilíngue" em vez de "multilíngue": enquanto para o multilinguismo, conforme entendido no Ocidente, as diferentes línguas são sistemas separados e autônomos, para 
o plurilinguismo, as línguas estão profundamente relacionadas e formam práticas gramaticais e comunicativas híbridas (CANAGARAJAH; ASHTRAF, 2013, p. 276).

Da mesma maneira, a Índia não tem uma tradição literária nacional única, mas várias tradições nas diferentes línguas faladas no seu território. Apesar de existir uma relação hierárquica entre todas elas, há também uma relação dialógica. Indra Choudhuri aponta que na Índia existe uma "unidade de expressão literária apesar das variedades linguísticas" (CHOUDHURI, 1997, p. 440). O que realmente atua como elo entre todas essas línguas, argumenta a autora, não é a imposição de uma única língua como o hindi, a língua oficial da Índia, ou o inglês, ou favorecer algumas línguas em detrimento de outras que são reduzidas à condição de dialetos, mas a tradução entre todas elas, o que contribui para encorajar "um padrão de comunicação inter-regional e inter-étnico" (CHOUDHURI, 1997, p. 440).

Para Devy (1997) a tradução tem um papel fundamental na Índia, em geral, e nos estudos literários, em particular, especialmente para o grupo de literaturas que ele define como Para: "tradições literárias menos conhecidas, estilos literários considerados como periféricos e não canônicos" (DEVY, 1997, p. 395). Em outras palavras, tradições literárias consideradas como menores pelo fato de estarem articuladas nas chamadas línguas vernáculas ou regionais. A relação entre essas literaturas canônicas e nãocanônicas, também definidas como Deshi e Marga, respectivamente, é altamente flutuante e muda seu status dentro da nação, do mesmo modo que as línguas.

Devy (1999) ainda aponta que existe uma relação dialética entre esses dois corpos de narrativas literárias que formam a espinha dorsal da história da literatura indiana baseada na epistemologia indiana da não-dualidade (DEVY, 1999, p. 395). Se Para é um termo usado nos estudos literários indianos para se referir às literaturas não canônicas, consideradas como a alteridade, o Outro, todos os textos, religiosos e seculares, que conformam a tradição, são parte de uma tradição maior que contém todos e não exclui nenhum (DEVY, 1997, p. 398). Essa visão sobre a literatura coincide com o conceito de plurilinguismo (CANAGARAJAH; ASHTRAF, 2013). Suresh Canagarajah (2011) expande o conceito ao observar que, separa os falantes plurilíngues, as línguas não são unidades independentes e isoladas, a competência linguística é entendida como um sistema de "multicompetências" que funciona simbioticamente para as diferentes línguas que formam o repertório local, enquanto a proficiência linguística 
está focada na construção desses repertórios em vez de o domínio total de cada língua (CANAGARAJAH, 2011, p.1).

A respeito da tradução, para a historiografia literária europeia, baseada na ideia da tradição nacional única, o que conta no processo tradutório é o original, o texto de partida; já na Índia, diz Devy (1997),

“...[algumas] das narrativas literárias mais respeitadas originaram-se em tentativas de traduzir os clássicos da literatura indiana para as línguas vernáculas como o Ramayana, de Kambari, para a língua kannada, o Ramayana, de Tulsi, para o hindi, e o Gitanjali, de Tagore, para o inglês (p. 400), entre outros muitos exemplos. Assim, a literatura em tradução é mais a norma do que a exceção na Índia, e o texto traduzido é visto como "...a revitalização do original em outro espaço verbal e temporal" (DEVY, 1997, p. 405).

Quando enredo, histórias e personagens ganham vida em uma outra língua e contexto cultural, desconstruindo, assim, o conceito de originalidade ao colocar a narrativa literária de partida e as suas muitas traduções no mesmo patamar.

No entanto, a tradução também é uma área de conflito. Para críticos como Choudhuri (1997, p. 440), favorecer uma única língua de tradução, como o inglês, significa ignorar a identidade plurilíngue da Índia e silenciar novamente muitas das línguas indianas que perdem para as línguas hegemônicas. É por isso que a autora, como muitos outros críticos, defende uma política de tradução inter-regional e interétnica, segundo a qual as línguas são traduzidas entre si de maneira complementar e não hierárquica. Contudo, o que deve ser lembrado é que o inglês da Índia é reconhecido não somente como uma das línguas vernáculas, bhashas, mas também uma língua veicular entre todas as línguas indianas.

Em seu monumental livro Women Writing in India (1991, xxii), Susie Tharu \& K. Lalita reúnem narrativas escritas por mulheres indianas, nas línguas vernáculas da Índia traduzidas para o inglês, desde o ano 600, antes de Cristo, até o século vinte. Nessa obra, as autoras afirmam que, ao traduzir uma língua regional para o inglês, estão representando uma cultura regional para uma cultura nacional ou indiana mais poderosa e, quando essa tradução cruza as fronteiras nacionais, estão representando a sua cultura nacional para uma cultura internacional ocidental ainda mais poderosa. Para não reduzir a cultura regional a estereótipos, as editoras favoreceram traduções que, em vez de domesticar as narrativas literárias, para se ajustar a modelos pan-indianos ou internacionais, demandam do leitor sua própria auto tradução para outro etos sócio 
histórico. Noutras palavras, por meio da contextualização histórica e social dessas narrativas, pedem que o leitor tente vivenciar o modo de vida dessas mulheres escritoras e suas personagens em vez de somente ler sobre elas.

As traduções de alguns textos chaves, assim como organizações de editores e tradutores, em várias partes do mundo, têm sido fundamentais para produzir mudanças nas sociedades em que as traduções são realizadas (TYMOCKZO, 2006, p. 442). Esses movimentos são formados por tradutores engajados que têm feito traduções de narrativas que questionam as instituições dominantes de sua sociedade. São tradutores, profissionais e não profissionais que, com suas traduções, contribuem para causas humanitárias. O que os une é seu desejo de dar visibilidade a determinados tipos de narrativas que, no futuro, possam se transformar em narrativas mais justas que ajudem a transformar a sociedade onde foram feitas (BAKER, 2006, p. 462-463). Assim entendida, a tradução não é somente um processo intercultural, no sentido de que relaciona culturas diferentes, mas também um processo intracultural. Se, por um lado, procura-se que a tradução para outras línguas chame a atenção da audiência internacional para determinados conflitos; por outro lado, as traduções sempre acontecem em um determinado contexto cultural e seu primeiro objetivo é sempre atender às necessidades dessa comunidade de partida (BAKER, 2006, p. 425).

Essa abordagem à tradução torna-se também evidente no caso das traduções de histórias escritas por mulheres, nas diferentes línguas vernáculas do subcontinente e no inglês da Índia e da diáspora, que têm como objetivo resistir ao sistema patriarcal. Uma dessas organizações é Stree Katha Books, fundada por Geeta Dharamarajan em Nova Delhi no ano de 1989. Stree Katha é parte da ONG Katha, cujos objetivos são o melhoramento da comunidade, o bem-estar das crianças, o desenvolvimento de projetos liderados por mulheres, a educação e a literatura. Stree Katha dedica-se à tradução de literatura infantil, mas também à tradução de histórias da Índia contemporânea, folclore e mitologia escritos em 21 línguas regionais e traduzidas em particular para a língua inglesa. Dessa maneira, tanto o trabalho desses escritores, como o predicamento de mulheres e crianças, tornaram-se conhecidos além da própria comunidade.

Uma das publicações mais importantes de Katha, conjuntamente à editora Garutman, foi o livro de contos Separate Journeys, traduzidos das línguas regionais e que teve três edições $(1991 ; 1998 ; 2004)$. A "Introdução" à segunda edição foi escrita pela fundadora de Katha, Geeta Darmarajan. Nela, a editora faz uma referência aos 
Vedas, os textos sagrados da Índia, nos quais são estabelecidos os rígidos códigos de conduta que, em sua opinião, ainda hoje mantêm a mulher cativa na vida e na literatura (DARMARAJAN, 1998, p. xxv). Darmarajan acrescenta que pouco mudou nos últimos dois mil anos para a maioria das mulheres, ao ponto de que ainda hoje uma mulher escritora precisa mostrar que ela é "decente". Isso explica o estilo fantasioso de muitas histórias escritas por mulheres ou o fato de que os seus enredos apresentam uma visão da sociedade nem sempre crítica. Contudo, o que distingue Separate Journeys desses livros é que evidencia o fato de que as escritoras indianas já não precisam disfarçar o seu discurso para dizer o que desejam (DARMARAJAN, 1998, xxvi). Assim, cada um dos contos, ou das viagens implícitas no nome do livro, leva escritoras e leitoras a vivenciar situações por todas conhecidas, embora muitas vezes reprimidas, ao mesmo tempo que aponta o caminho para possíveis transformações ou mudanças quando, por meio do discurso literário em tradução, o privado entra no espaço do público para se tornar uma denúncia.

$\mathrm{Na}$ "Introdução" de Separate Journeys, da edição de 2004 (University of South Carolina), Mary Ellis Gibson faz questão de observar que, tanto Garutmän como Stree Katha, são organizações que promovem a tradução como uma forma de inclusão e transformação social (GIBSON, 2004, p.viii). Garutmän não somente publica livros sem fins lucrativos como também promove a tradução das línguas indianas por meio de oficinas para tradutores e a edição e distribuição dessas traduções. Por sua vez, um dos objetivos de Stree Katha é espalhar o amor pelos livros, a alegria da leitura entre crianças e adultos por meio da publicação de livros, revistas e panfletos relacionados a temas sobre a condição das mulheres em todas as línguas vernáculas da Índia. As temáticas dessas narrativas, como é o caso de Separate Journeys, têm a ver com conflitos comunalistas e diversas manifestações de injustiças. Esses objetivos alinhamse à missão da ONG Katha, que é melhorar a vida de crianças e mulheres que precisam ganhar o seu sustento (DHARMARAJAN, 1998, p. viii).

Estabelecida em 1984, Kali for Women é definida no seu site online como uma editora feminista que publica sobre e para mulheres. Fundada por Urvashi Butalia e Ritu Menon em 1984, e logo dividida em 2003 em duas novas editoras, Women Unlimited, de Menon, e Zubaan, de Butalia, o objetivo dessa editora era que as vozes das mulheres indianas fossem escutadas por meio da publicação de obras acadêmicas engajadas e de obras de ficção, no original e em tradução. Como Butalia \& Menon (1990) apontam no 
"Prefácio" de The Slate of Life. More Contemporary Stories by Women Writers of India, uma de suas maiores satisfações sempre tem sido descobrir escritoras desconhecidas, ainda não traduzidas, em uma das línguas da Índia (BUTALIA; MENON, 1990, p. VIII). Seu pioneirismo foi prontamente seguido por outras editoras, focadas também em temas sociais e de gênero, como Bhakaland Send e Tulika Books. Para Butalia e Menon, a publicação de livros de autoria feminina e sobre temas relacionados ao mundo da mulher, assim como a sua tradução, é um caminho para conscientizar a sociedade indiana sobre a condição da mulher na Índia.

Um dos livros mais emblemáticos publicados por Kali for Women é Shareer ki Jaankari (Know your Body), que foi narrado por setenta e cinco mulheres da área rural do Rajasthan, muitas delas analfabetas. Foi uma ativista feminina do norte da Índia, Mahila Samuh, que levou para as editoras o trabalho dessas mulheres. Seu desejo era que o livro fosse publicado para que pudesse ser distribuído entre todas as mulheres indianas. Shareer ki Jaankari é um dos primeiros livros a falar sobre o corpo humano e temas tabu na Índia, como a menstruação. Por meio de textos e desenhos, o livro mostra as mudanças pelas quais o corpo feminino passa através do tempo (BUTALIA; MENON, 1994, p. 57). Como na Índia não pode ser mostrado o corpo nu, nos desenhos, homens e mulheres aparecem vestidos, mas, por meio de abas que podem ser abertas, a publicação revela as diferentes partes do corpo. Originalmente escrito em hindi, o livro foi traduzido para as línguas bengali, hindi e oriya. Hoje é distribuído gratuitamente por meio de ONGs.

Entre as várias publicações de Kali for Women,destacam-se duas coletâneas de contos, Truth Tales. Contemporary Stories by Women Writers in India (1986) e The Slate of Life. More Contemporary Stories by Women Writers of India (1990). O que motivou o primeiro dos livros, conforme é apontado no seu "Prefácio", foi o grande número de contos nas línguas regionais que representavam as tendências mais dinâmicas da literatura indiana, mas que nunca tinham circulado fora de suas regiões (ALEXANDER, 1986, p. 07). O que importava para as editoras era a relação entre essa escrita e o engajamento político das escritoras, em particular, descobrir até que ponto elas achavam que suas narrativas eram capazes de mudar a sua sociedade.

Os sete contos da coleção foram escritos originalmente em algumas das línguas mais importantes da Índia: bengali, gujarati, marata, hindi, urdu e tâmil. A seleção inclui também contos em inglês. Essas línguas representam diferentes áreas do 
subcontinente e mostram a vida em áreas rurais e urbanas e em pequenas e grandes cidades. Por sua vez, os contos refletem os aspectos em comum da vida das mulheres, apesar de pertencerem a comunidades afastadas entre si com diferentes modus vivendi. Ao revelar uma identidade em comum entre todas elas, a escrita literária e sua tradução tornam-se uma base para uma possível ação política.

A respeito da segunda coletânea, The Slate of Life (1990), semelhante a Truth Tales, é também parte do empenho das editoras de publicar contos de autoria feminina em tradução para o inglês e escritos nas várias línguas da Índia. O valor dessas narrativas, como apontam Butalia \& Menon (1990) na "Introdução", reside não somente na sua criatividade, mas na visão que essas autoras têm sobre a sua sociedade, assim como os costumes que desafiam com suas narrativas: "uma escrita que é intensamente pessoal, mas, ao mesmo tempo, política; um estilo de escrita que, em uma sociedade patriarcal, é considerada subversiva" (BUTALIA; MENON, 1990, p. VII). Os contos da antologia foram escritos em inglês, urdu, oriya, hindi, malayalam, punjabi, tâmil, assamese, gujarati e bengali. A partir de sua tradução para o inglês, eles foram retraduzidos para o francês, alemão e espanhol. O alcance do livro é tanto intracultural quanto intercultural. Para as editoras, a tradução de todas essas narrativas tem dado origem a sérias reflexões sobre a condição da mulher na Índia e tem se tornado tema de pesquisa nos centros de estudos feministas de várias universidades nacionais e internacionais (BUTALIA; MENON, 1990, p. VIII).

$\mathrm{Na}$ Introdução do livro, intitulada Lives of their Own ["Vidas Próprias"], Chandra Talpade Mohanty e Satya P. Mohanty apontam que, ao discutir temas como a identidade de gênero, denunciar a exploração sexual e a violência física e psicológica, assim como formas menos óbvias de poder cultural e simbólico, essas narrativas e suas traduções encorajam o leitor a procurar novas maneiras de imaginar a família, a comunidade e a nação (MOHANTY; MOHANTY, 1990, p. 01). É por isso que todos os contos escolhidos para tradução e publicação na antologia retratam temáticas como gênero, experiência e identidade, sexualidade, propriedade e liberdade, e visões de comunidade e autonomia (MOHANTY; MOHANTY, 1990, p. 03).

Por sua vez, o gênero "conto" é significativo em todas as antologias. Por um lado, é de fácil publicação em jornais e revistas que têm uma grande circulação regional e nacional e podem chegar a uma grande audiência. Por outro lado, pelo fato de serem narrativas curtas, facilitam o processo de escrita das autoras, já que podem ser 
elaboradas enquanto fazem suas tarefas domésticas e atendem a suas famílias. Essa característica do gênero também facilita o processo de tradução.

Os projetos de Stree Katha e Kali for Women mostram que a prática da tradução literária não é somente linguística e estética, mas ética e ideológica porque é um modo de resistência e luta contra a condição da mulher na sociedade. Vista dessa maneira, a tradução de contos de autoria feminina pode ser entendida como um contra discurso frente às atitudes repressivas da sociedade. Ao contribuir para o que Gayatri Spivak define como a "solidariedade teórica entre as mulheres" (apud GIBSON, 2004, p. xiv), as narrativas literárias e as suas traduções vão além dos limites da ficção quando transformam a experiência individual em uma questão social que, eventualmente, leva à conscientização da sociedade e sua mudança.

\section{CONCLUSÃO}

O objetivo deste artigo foi pensar a tradução enquanto meio de representação da resistência aos modelos tradicionais de produção de conhecimento por determinados grupos hegemônicos, e também enquanto promotora da inclusão social de mulheres em dois contextos sociolinguístico-culturais distintos: 1) na apropriação da peça shakespeariana Romeu e Julieta por uma mulher brasileira de terceira idade, que, em um movimento de expansão interpretativa, ressignifica a peça shakespeariana, seu endereçamento e seu enredo, a partir de uma perspectiva social e ideológica, e em uma versão da língua portuguesa que mostra nuances de diferentes registros da língua portuguesa; 2) nas traduções de contos escritos por mulheres e sobre mulheres nas bhashas, línguas vernáculas da Índia; nelas, o plurilinguismo fica de manifesto no fato de que não são necessariamente traduzidas para uma versão padrão da língua inglesa, e de que na tradução para outras línguas regionais, ainda há marcas das outras bhashas; 3) essas traduções não somente chamam a atenção da comunidade nacional e internacional, mas também provocam mudanças na comunidade local onde se originaram. O que ambos os exemplos têm em comum é que olham para a tradução como representação não apenas de um ato linguístico, de prática literária ou de comoditização do texto literário em tradução, mas, sobretudo, ético e político porque transforma, empodera e faz (sobre)viver as mulheres de comunidades "minoritarizadas". No primeiro caso, esse processo se manifesta nas mudanças que acontecem nas obras literárias, em forma e 
conteúdo, devido à sua migração temporal, espacial, linguística e de estilo por meio da tradução. No segundo caso, manifesta-se na circulação de narrativas literárias em tradução que permitem que escritoras da mesma nação possam se reconhecer nas histórias de outras mulheres, também indianas, mas de comunidades diferentes, e unir forças para lutar contra diferentes formas de subjugação.Assim, nos dois contextos, a tradução é vista como um movimento de descentralização e deslocamento que contribui para colocar comunidades, histórias, temáticas, autores e tradutores em um pé de igualdade.

\section{REFERÊNCIAS}

ALEXANDER, M. "Preface". Truth Tales. Contemporary Stories by Women Writers of India. Meena Alexander, ed. New York: The Feminist Press at the City University of New York,1986, p.7-9.

BAKER, M. "Translation and Activism: Emerging Patterns of a Narrative Community". The Massachusetts Review Vol. 47, No. 3, 2006, p. 462-484.

BOITO, F.; MARINS, L. Expansão interpretativa e tradução: pluralidade e descentrismo. PERcursos Linguísticos. Vitória, n. 16, p. 124-135, 2017.

BOURDIEU, P. A economia das trocas simbólicas. Tradução de Sérgio Miceli, Silvia de Almeida Prado, Sônia Miceli e Wilson Campos Vieira. São Paulo: Perspectiva, 2007.

BUTAliA, U.; MENON, R. eds. Preface. The Slate of Life. New Delhi: Kali for Women, 1990.

BUTALIA, U.; MENON, R. A Valuable Lesson. Focus on Gender, v.2, n.2, 1994, p.57.

CANAGARAJAH, S.; ASHTRAF, H. "Multilingualism and Education in South Asia: Resolving Policy/Practice Dilemmas". Annual Review of Applied Linguistics. Cambridge University Press, N.33, p. 258-285, 2013.

CANAGARAJAH, S. Translanguaging in the Classroom: Emerging Issues for Research and Pedagogy. In: Applied Linguistics Review. May 2011, p. 1-27

CHOUDHURI, I. The Plurality of Languages and Literatures in Translation: The Post-colonial Context. In: Meta: Translators' Journal, vol. 42, n 2, 1997, p. 439-443.

CORACINI, M. J. Vozes (des)ordenadas e (in)fames. In: MIANEZ, N; GASPAR, N. R. (Ors.) A (des)ordem do discurso. São Paulo: Contexto, 2010, p. 105-126. 
DHARMARAJAN, G. Introduction. Separate Journeys. New Delhi: Katha \& Garutman, 1998, p. xxv-xxviii.

DEVY, G. N. Literary History and Translation: An Indian View. In: Meta, XI. II, 1997, p.395-405.

DERRIDA, J. Torres de Babel. Tradução de Junia Barreto. Minas Gerais: Ed. da UFMG, 2005.

FELSKI, R. Uses of literature. Oxford: Blackwell Publishing, 2008.

FESTINO, C. G. Dalit Women. Life Narratives and Literature as Experience. Acta Scientiarum. Language and Culture. Maringá, v. 37, n. 1, p. 25-36, Jan.-Mar., 2015.

GADAMER, H. G. Verdade e método: traços fundamentais de uma hermenêutica filosófica. Tradução de Enio Paulo Giachini. Rio de Janeiro: Vozes, 2002.

MARINS; L. C.; PRADO, M. R. Literatura na rede: convergência, teoria e ensino. Revista de Letras Dom Alberto. Santa Cruz do Sul, v. 1. n. 3. p. 320-332, 2013.

GIBSON, M. E. Introduction. In: Geeta Dharmarajan (Ed). Separate Journeys. University of South Carolina Press, 2004, p. vii-xxiv.

RAJAGOPALAN, K. Por uma lingüística crítica: linguagem, identidade e questão ética. São Paulo: Parábola Editorial, 2003.

MOHANTY, C. T.; S.P.MOHANTY. Introduction. Lives of their Own. In: BUTALIA, U.; MENON, R. (eds.) The Slate of Life. New Delhi: Kali for Women, 1990, p.1-25.

MONTE MÓR, W. Crítica e Letramentos Críticos: Reflexões Preliminares. In: ROCHA, C. H; MACIEL, R. F. (Org.). Língua Estrangeira e Formação Cidadã: por entre discursos e práticas. $2^{\mathrm{a}} \mathrm{ed}$. Campinas: Pontes Editores, 2015, p. 31-50.

MONTE MÓR, W. Sobre rupturas e expansão na visão de mundo: seguindo as pegadas e os rastros da formação crítica. In: PESSOA, R.; SILVESTRE, V.; MONTE MÓR, W. Perspectivas críticas de educação linguística no Brasil: trajetórias e práticas de professoras/es universitárias/os no Brasil. 1 ed. São Paulo: Pá de Palavra, 2018. p. 263276.

QUINE, W. V. O. Meaning and translation. In: VENUTI, L. (Org.) The Translation Studies Reader. London, New York: Routledge, 2000, p. 94-112.

SOBRAL, A. Dizer o 'mesmo' a outros: ensaios sobre tradução: ensaios sobre tradução.São Paulo: SBS, 2008.

THARU, S.; K. LALITA (Eds). Preface. In: Women Writing in India. 600 B. C. to the Present. Volume 1: 600 B. C. to the Early $20^{\text {th }}$ Century. New York: The Feminist Press at the City University of New York, 1991, p. xvii-xxvi. 
TYMOCKZO, M. Translation and Political Engagement. Activism, Social Change and the Role of Translation in Geopolitical Shifts. The Massachusetts Review, Vol. 47, No. 3 , 2006, p. 442-461.

VELLAS, P. As oportunidades da terceira idade. Maringá: Ed. UEM, 2009.

\section{ENDEREÇOS ELETRÔNICOS}

KATHA BOOKS. Disponível em https://en.wikipedia.org/wiki/Katha_Books. Acesso em: 14 maio, 2019.

KALI FOR WOMEN. Disponível em https://en.wikipedia.org/wiki/Kali_for_Women. Acesso em: 14 maio, 2019. 